\title{
Canada's chief doctor cared for the health of a nation but neglected his own
}

I f Dr. David Butler-Jones could change anything about his nine years as the face of public health in Canada, he would have paid more attention to his own health.

"I guess I probably should have taken a bit better care of myself," says ButlerJones, 59, who is stepping down as the first-ever Chief Public Health Officer of Canada, one year after suffering a stroke.

He recalls the summer of 2009 , when he was urging staffers to take time off to fortify themselves for a busy fall as the Public Health Agency of Canada prepared to contend with $\mathrm{H} 1 \mathrm{~N} 1$ - the biggest global flu pandemic in more than four decades.

Butler-Jones, however, refused to take vacation himself. He was newly divorced and thought the best way to cope was to keep working.

"That's just not very smart. Doctors don't always make the best patients," concedes Butler-Jones. "If there was one thing I would do differently, I would have taken the time to make sure I got what I needed."

While he has "recovered enormously," he says, he no longer has the stamina for the long hours, extensive travel and other demands of his job.

"I have to be realistic about that and be fair to the country and fair to myself, because the worst thing I could do is to persist and keep hoping, and then we get into another crisis and I'm not up to it," he says.

Butler-Jones will continue in his job until his successor is chosen, and then work part-time as an advisor to the agency, which was set up following the 2003 SARS crisis to improve and coordinate the public health response across Canada.

As the agency's founding chief medical officer, Butler-Jones has been the government's main coordinator and key spokesperson through several public health crises, including the 2008 liste- riosis outbreak and the H1N1 pandemic. The H1N1 response, says Butler-Jones, was one of the agency's biggest accomplishments. As panicked Canadians lined up for hours at makeshift immunization clinics, ButlerJones was widely recognized as the national face of information and mobilization against the contagion.

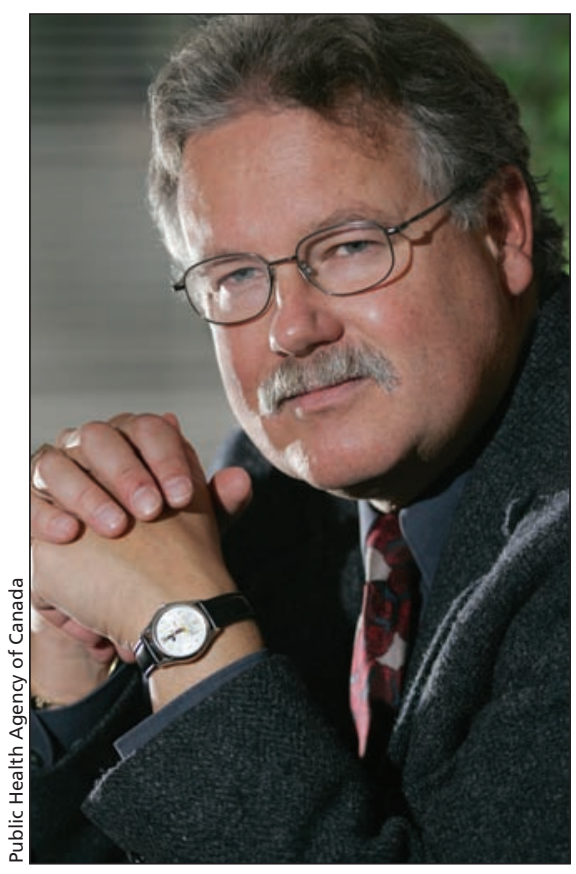

Dr. David Butler-Jones, 59, is stepping down as the first-ever chief public health officer of Canada at the Public Health Agency of Canada, one year after suffering a stroke.

In parting, Butler-Jones says that handling pandemics is not the agency's only role. For the last decade, it has encouraged interprovincial cooperation between health officers on day-to-day issues, including infectious diseases, childhood obesity, tuberculosis and antibiotic resistance.

"I think [he] was the right person in the right place at the right time," says Dr. Perry Kendall, British Columbia's provincial health officer, who applauded
Butler-Jones for championing cooperation between provinces and inspiring confidence among health officers and politicians alike.

"I would say as the first chief public health officer, [he] did groundbreaking work," says Ian Culbert, executive director of the Canadian Public Health Association. "It was crucial, as a number one job, that the agency be able to respond to emergencies with credibility and be able to reassure Canadians that the agency was protecting their health from these events. I think he did that extremely well. It wasn't like he was taking over something that was already established; he was creating something."

Culbert credits Butler-Jones with contributing "a new mindset, in reorienting the profession, in saying we're not just the needle-jabbers and the sexed people anymore, that public health was really coming of age."

Dr. Anna Reid, president of the Canadian Medical Association, said in a statement that the public health agency under Butler-Jones's leadership became an internationally recognized centre, particularly in its acclaimed response to the H1N1 flu pandemic.

"Dr. Butler-Jones has spoken first and foremost for the needs of Canadians," said Reid. "His annual reports to Parliament ... have shone a spotlight on important issues such as health inequality, priorities for a healthy future and the needs of older Canadians and our youth."

Butler-Jones says he has a "long list" of advice he will give to his successor, including a belief in the oftenquoted adage to "gather around you as many people smarter than you as you can, who are comfortable and willing to tell you what you need to hear, not necessarily what you want to hear." Janice Tibbetts, Ottawa, Ont.

CMAJ 2013. DOI:10.1503/cmaj.109-4541 